\title{
Perancangan Desain Tas Dengan Pendekatan Strategi Blue Ocean
}

\author{
Devanny Gumulya dan Jeny Angreini \\ Desain Produk, Fakultas Desain, Universitas Pelita Harapan \\ e-mail: devanny.gumulya@uph.edu
}

\begin{abstract}
Abstrak-Desain produk adalah keilmuan yang selalu mencari inovasi dan kebaruan dalam prosesnya. Blue Ocean Strategy (BOS) adalah strategi bisnis mencari pasar baru dengan menawarkan nilai yang berbeda dari kompetitor lainnya. Paper ini menghubungkan kerangka pemikiran BOS dalam proses desain. Empat langkah kunci dari BOS adalah eliminasi, kurangi, tingkatkan dan ciptakan. Langkah-langkah ini di implementasi pada proses pencarian ide untuk perancangan tas. Dari pendekatan BOS, proses desain menjadi lebih terarah, terstruktur dan nilai inovasi dari produk dapat didapatkan dengan cepat. Hasil dari paper ini adalah rancangan desain tas yang inovatif dengan sistem mekanisme yang dapat merubah tas dalam tiga bentuk, sehingga tas dapat digunakan untuk aktivitas sehari-hari juga aktivitas pada akhir pekan.
\end{abstract}

Kata Kunci - Desain produk, strategi blue ocean, proses desain, tas

\begin{abstract}
Industrial design is a discipline that always looks for innovation and novelty within the process. Blue Ocean Strategy (BOS) is a business strategy looking for new markets by offering different values than other competitors. This Paper connects the BOSS's framework in the design process. The four key steps of the $B O S$ are the elimination, reducing, upgrading and creating. These steps are implemented in the design process. In the BOS approach, the design process becomes more directional, structured and the product concept innovativeness can be obtained quickly. The result of this paper is bag for young millennials with new innovative mechanism that allow the bag with 3 forms therefore it can be used for daily and leisure activities.
\end{abstract}

Keywords - Industrial design, blue ocean strategy, design process, bag

\section{PENDAHULUAN}

Blue Ocean Strategy (BOS) adalah sebuah strategi konsep yang diperkenalkan di pertengahan tahun 2004 oleh W. Chan Kim dan Renee Mauborgone, dua professor dari sekolah bisnis di Perancis bernama INSEAD [1]. Konsep BOS muncul sebagai konsep baru di dogma strategi manajemen yang tidak berubah puluhan tahun. Ide dari BOS adalah daripada terus berkompetisi dengan pesaing di pasar yang sudah penuh dengan pesaing, lebih baik membuka pasar baru yang belum ada pesaing yang disebut dengan "blue oceans". Sejak diluncurkan di tahun 2004, BOS menarik banyak perhatian dan telah banyak diaplikasikan di dunia bisnis dan dipelajari di studi manajemen di tingkat universitas.

Disisi lain, desain produk berperan penting pada membentuk persepsi konsumen pada brand [2]. Dalam perspektif ini, desain produk menjadi penting untuk mengkomunikasikan keunikan sebuah bisnis, karena desain produk termasuk dalam nilai yang ditawarkan bisnis pada pasar baru yang dimaksud BOS. Tujuan dari paper ini adalah menghubungkan metode BOS dalam proses perancangan desain produk agar menghasilkan produk inovatif dan menciptakan pasar baru yang tidak ada pesaing. Peneliti melihat bahwa dengan pendekatan interdisiplin antara manajemen dan desain produk, pembelajaran positif dapat dihasilkan dan memperkaya masing - masing ilmu.

Untuk menciptakan pasar baru, BOS mempunyai empat langkah sebagai berikut [3]:

1. Eliminasi

Fitur umum dari industri sejenis yang harus dihilangkan.

2. Kurangi

Fitur yang sebaiknya dikurangi dari standar umum industri sejenis.

3. Tingkatkan

Fitur yang perlu ditingkatkan diatas standar industri sejenis.

4. Ciptakan

Fitur baru yang belum pernah ditawarkan industri sejenis.

Dengan berpikir dengan kerangka ini nilai baru akan terbentuk dan menciptakan pasar baru. Dalam melakukan empat langkah ini BOS memperkenalkan enam kerangka berpikir yang membedakan BOS berbeda dengan red ocean.

Aplikasi BOS yang umum dibahas sebagai kasus BOS yang sukses adalah pada Circus De Soleil. Pada tahun 2000an, industri sirkus terus menurun, banyak perusahaan sirkus yang tutup. Permasalahan semakin kompleks karena banyak nya protes atas kekerasan binatang pada atraksi sirkus. Circus $d u$ Soleil adalah sirkus yang didirikan sejak tahun 1984 oleh Guy Laliberté dan Gilles Ste-Croix dan tetap bertahan hingga sekarang, karena telah menerapkan strategi BOS. Circus du Soleil menerapkan empat langkah BOS sebagai berikut :

1. Eliminasi

Menghapus binatang dan pemain ternama dalam atraksi sirkus yang banyak menghabiskan biaya perawatan

2. Kurangi

Mengurangi humor dan risiko bahaya dalam acara sirkus

3. Tingkatkan

Meningkatkan desain tenda yang unik dengan tempat duduk yang nyaman dengan bahan yang premium.

4. Ciptakan

Menciptakan tema - tema atraksi dan pertunjukkan musik yang artistik dengan dan relevan dengan jaman 
sekarang. Tenda dilengkapi dengan dengan teknologi pencahayaan dan akustik terkini.

Perbedaan antara strategi Red Ocean dan Blue Ocean dapat dilihat pada Tabel 1.

Tabel 1. Komponen-komponen pada Red Ocean dan Blue Ocean.

\begin{tabular}{|c|c|c|}
\hline Komponen & Red Ocean & Blue Ocean \\
\hline Industri & $\begin{array}{l}\text { Fokus pada } \\
\text { kompetisi sejenis } \\
\text { dalam industri }\end{array}$ & $\begin{array}{l}\text { Melihat pada } \\
\text { industri diluar } \\
\text { industri sejenis }\end{array}$ \\
\hline $\begin{array}{l}\text { Group } \\
\text { strategis }\end{array}$ & $\begin{array}{l}\text { Fokus pada posisi } \\
\text { kompetitif dalam } \\
\text { group strategis }\end{array}$ & $\begin{array}{l}\text { Melihat diluar } \\
\text { group strategis } \\
\text { diluar industri } \\
\text { sejenis }\end{array}$ \\
\hline Pembeli & $\begin{array}{l}\text { Fokus } \\
\text { meningkatkan } \\
\text { layanan group } \\
\text { pembeli }\end{array}$ & $\begin{array}{l}\text { Mencari group } \\
\text { pembeli yang } \\
\text { lain }\end{array}$ \\
\hline $\begin{array}{l}\text { Cakupan } \\
\text { produk dan } \\
\text { servis }\end{array}$ & $\begin{array}{l}\text { Fokus } \\
\text { memaksimalkan } \\
\text { nilai dari produk } \\
\text { dan servis dalam } \\
\text { Batasan industri }\end{array}$ & $\begin{array}{l}\text { Mencari produk } \\
\text { dan servis } \\
\text { komplementer }\end{array}$ \\
\hline $\begin{array}{l}\text { Orientasi } \\
\text { fungsi dan } \\
\text { emosi }\end{array}$ & $\begin{array}{l}\text { Fokus } \\
\text { meningkatkan } \\
\text { orientasi fungsi, } \\
\text { emosi dan harga }\end{array}$ & $\begin{array}{l}\text { Memikirkan } \\
\text { ulang orientasi } \\
\text { fungsi dan } \\
\text { emosi }\end{array}$ \\
\hline Waktu & $\begin{array}{l}\text { Fokus pada } \\
\text { adaptasi trend } \\
\text { external }\end{array}$ & $\begin{array}{l}\text { Membentuk } \\
\text { trend }\end{array}$ \\
\hline
\end{tabular}

Empat langkah BOS sering digambarkan pada grafik yang disebut dengan "BOS kanvas strategi", sehingga terlihat jelas perbedaan Cirques de Soleil yang menerapkan BOS dengan perusahaan sirkus lainnya (Gambar 1).

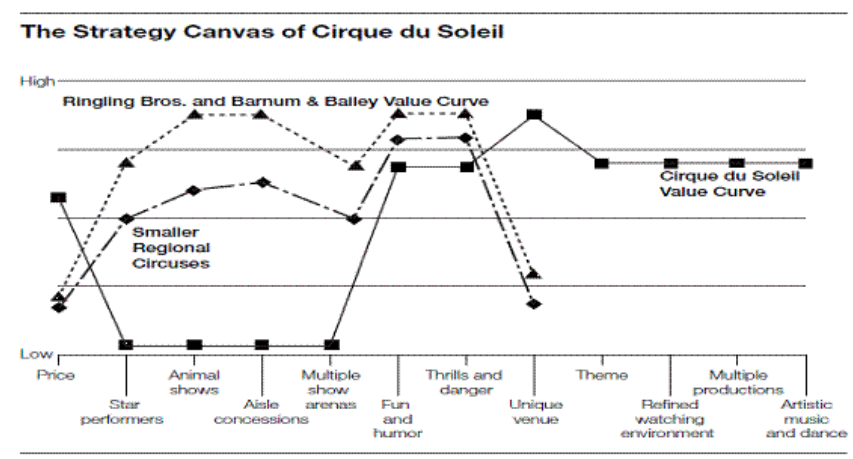

Gambar 1. Kanvas strategi BOS.

Sumber ; https://www.ivoryresearch.com/samples/a-critical-evaluation-ofblue-ocean-strategy-and-its-value-to-smes/

Dengan pendekatan BOS, Cirques De Soleil menarik kostumer baru bagi industri sirkus yaitu pasar penggemar opera dan teater, bukan lagi keluarga dan anak - anak yang ingin menonton pertunjukkan binatang dan badut. Dengan pertunjukkan yang elegan disertai dengan pesan intelektual Cirques De Soleil tetap bertahan selama 36 tahun sampai sekarang.

Di tahun 2017 BOS diperbaharui dengan ditambah tahapan tahapan proses menuju BOS, karena banyak industri yang mau menuju BOS tapi mengalami kesulitan untuk mengambil langkah yang dibutuhkan untuk menuju BOS [4]:

1. Proses awal

BOS dimulai dengan perubahan paradigma, berani memperluas horizon dan melihat keluar kesempatan di luar kondisi bisnis saat ini. Setelah paradigma yang tepat maka pemilihan tim yang tepat untuk memulai BOS.

2. Memahami kondisi sekarang

Memiliki pemahaman yang jelas akan situasi sekarang

3. Berimajinasi

Membayangkan masalah - masalah tersembunyi yang belum dijawab industri. Menemukan customer diluar industri

4. Mencari cara menuju BOS

Rekonstruksi batasan -batasan pasar secara sistematis. Buat opsi langkah BOS.

5. Lakukan langkah tes

Test langkah BOS di pasar dengan bisnis model yang baru.

Studi kasus BOS lainnya adalah pada Netflix. Layanan berlangganan siaran hiburan melalui layanan internet. Dari grafik ini dapat dilihat strategi BOS netflik yang berhasil merebut banyak customer tv kabel, karena menciptakan nilai kendali bagi customer untuk menonton kapan saja, tanpa diganggu iklan dan langsung dapat menonton semua episode secara penuh tanpa perlu menunggu seri baru di pekan mendatang (Gambar 2).

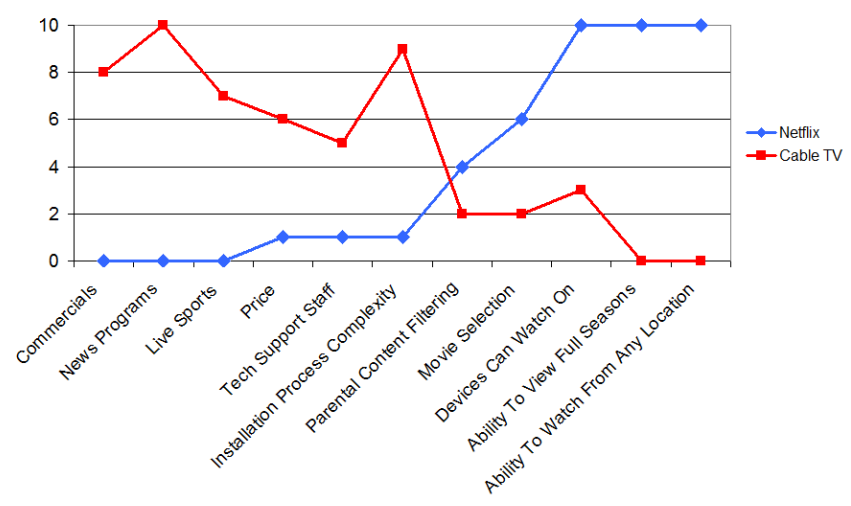

Gambar 2. Studi kasus BOS pada Netflix.

Sumber: https://profitworks.ca/blog/378-blue-ocean-strategy-formulationthe-strategy-canvas

\section{METODE}

Penelitian ini menggunakan pendekatan kualitatif yang bersifat eksploratori. Mengingat tujuan dari paper ini adalah untuk melihat bagaimana BOS dapat memperkuat proses pencarian ide pada perancangan produk. Proses penelitian adalah sebagai berikut:

1. Kajian literatur BOS

2. Metode BOS

3. Implementasi BOS pada pencarian ide perancangan tas.

4. Perancangan desain produk hasil dari dari BOS

5. Rekomendasi hasil penelitian.

Konsep dan eksekusi desain juga mengacu pada literatur terpilih [5], [6], dan [7]. 


\section{HASIL DAN PEMBAHASAN}

Strategi kanvas BOS diterapkan pada proses perancangan tas untuk masyarakat urban berusia 18- 30 tahun (Gambar 3).

\section{Profil target market}
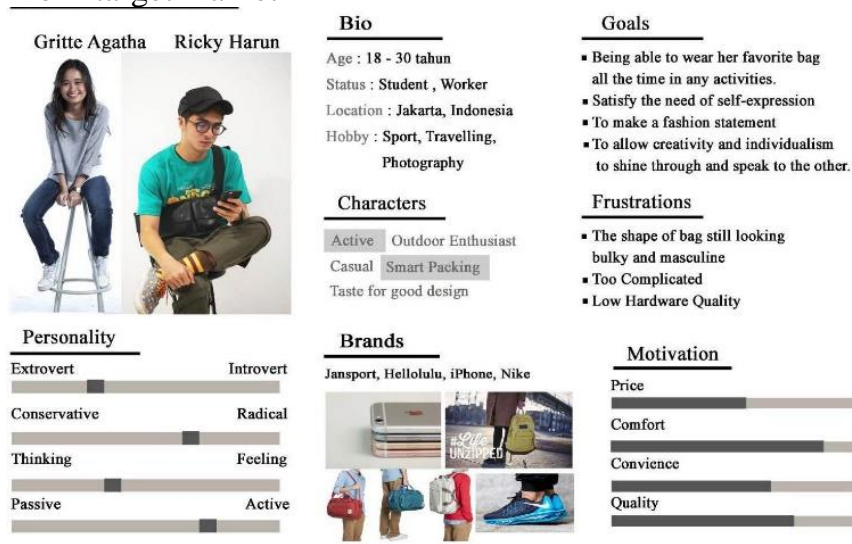

Gambar 3. Strategi kanvas BOS pada proses perancangan tas.

\section{Observasi dan Wawancara}

Observasi dan wawancara dilakukan pada masyarakat urban berusia 18 tahun dan 30 tahun untuk mengetahui gaya dan barang yang dibawa target market (Gambar 4).
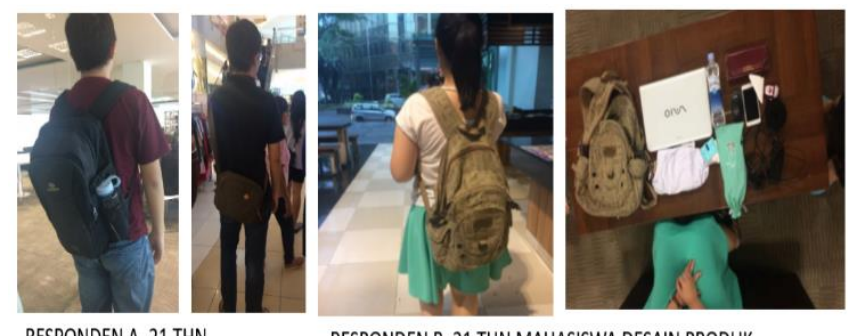

RESPONDEN A, 21 THN

RESPONDEN B, 21 THN MAHASISWA DESAIN PRODUK

MAHASISWA TEKNIK INDUSTRI
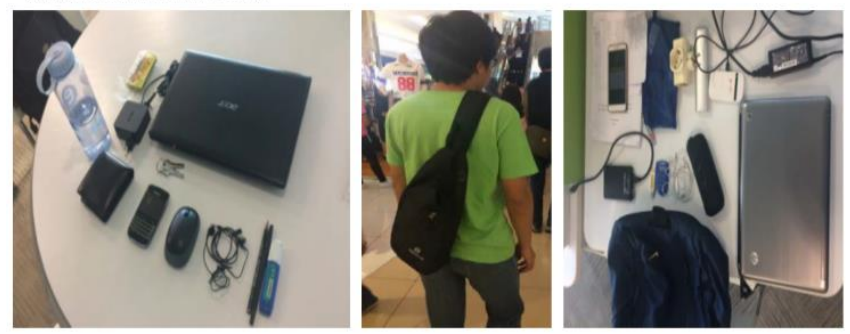

RESPONDEN C, 21 THN MAHASISWA TEKNIK INDUSTRI

Gambar 4. Sebagian aktivitas observasi dan wawancara.

Dari proses obervasi dan wawancara ditemukan tema - tema menarik terkait tas yang dimiliki responden.

\section{Functional}

Kriteria ini yang terus diucapkan tiga responden terkait tas yang dipakai untuk aktivitas rutin sehari - hari seperti berkuliah dan travelling. Tas dengan banyak kompartmen untuk menaruh benda - benda kecil yang dapat diakses dengan mudah. Tas diharapkan dapat mengakomodasi kegiatan setelah kampus seperti aktivitas olahraga seperti bermain futsal, ngegym, dan lain - lain.

\section{Light and Simple}

Tas yang ringan tidak berat dan stylish yang dibutuhkan responden untuk berpergian ke acara - acara di akhir pekan. Tas dengan gaya yang umum dapat dicocokkan dengan aneka suasana dan tema busana.

\section{Kisaran Budget}

Range budget yang responden mau keluarkan untuk tas adalah $500.000-2.500 .000$

\section{Penyimpanan berdasarkan intensitas pemakaian}

Lokasi penyimpanan tas berdasarkan intensitas penggunaan, bila sering digunakan tas akan diletakkan di ruang terbuka, seperti meja, gantungan baju, pegangan lemari. Bila tas jarang dipakai maka responden akan menyimpannya dalam lemari.

\section{Kuosioner}

Untuk mengetahui permasalahan terbesar yang terjadi pada saat penggunaan tas, maka dilakukan survey dengan membagikan kuosioner kepada 57 koresponden yang berdomisili di kawasan Jabodetabek dengan spesifikasi sebagai berikut:

Jenis Kelamin : Wanita dan Pria

Usia : 18-30 tahun

Pekerjaan : Mahasiswa dan Pekerja

Dari hasil kuisoner didapatkan data sebagai berikut:

1. $55 \%$ responden menggunakan tas punggung untuk aktivitas sehari - hari.

2. $70 \%$ responden memiliki tas $2-5$ buah, sehingga responden mengalami masalah penyimpanan tas.

3. Pertimbangan orang ketika membeli tas adalah fungsional $(56 \%)$, kenyamanan $(16 \%)$, kualitas buatan produk $(12 \%)$, desain tas yang bagus dan unik (10\%).

4. Alasan responden membeli tas baru adalah desain (30\%), membeli tipe tas yang belum dimiliki (23\%), dan pembelian yang bersifat impulsive karena bosan (17\%).

5. Kendala dari tas yang dimiliki material tas rusak (40\%), resleting rusak (30\%) dan tali tas yang tidak kuat (16\%).

6. Responden menyukai desain tas dengan bentuk geometris dan kaku $(67 \%)$, ornamental $(22 \%)$, detail anyaman $(10 \%)$.

Dari survei ini dapat disimpulkan beberapa hal sebagai berikut :

Responden menyukai tas yang fungsional yang pas dengan barang bawaan yang diperlukan untuk aktivitasnya sehari hari. Tas dengan desain yang unik dengan gaya minimalis. Namun responden karena memiliki banyak tas, maka Ia tidak merawat tasnya dan menyimpan seadanya sehingga material dan aksesoris tas menjadi mudah rusak.

Dari hasil wawancara, observasi dan kuisoner dapat disimpulkan beberapa indikator yang mempengaruhi pembelian tas pada seseorang adalah sebagai berikut:

1. Functional: kapasitas kompartemen, easy access, durabilitas bahan dan aksesoris tas

2. Style: minimalist dan universal, serta mudah di padu padankan dengan aneka busana. 
3. Intensitas penggunaan: semakin sering dipakai maka responden maka responden mementingkan unsur fungsi dari style.

Selanjutnya dilakukan studi tentang jenis-jenis tas yang ada di pasaran, dengan tujuan mengetahui karakter desain dari produk yang sudah ada di pasaran dianalisa dengan indicator yang sudah disebutkan sebelumnya. Dikumpulkan tas harga Rp. 500.000,00 sampai dengan Rp.1.000.000,00. Produk dinilai dari skala 1 (buruk) - 5 (baik sekali). Seperti dijelaskan pada Tabel 2 dan Gambar 5.

\begin{tabular}{|c|c|c|c|}
\hline Variabel & Tas A & Tas B & Tas C \\
\hline Kegunaan & 4 & 4 & 4 \\
\hline Ukuran & 5 & 5 & 5 \\
\hline Addaptasi & 2 & 2 & 4 \\
\hline Fitur tas & 4 & 4 & 3 \\
\hline Harga & 4 & 3 & 4 \\
\hline
\end{tabular}

Selanjutnya dilakukan empat langkah BOS: eliminasi, kurangi, tingkatan dan kreasi:

1. Eliminasi

Tas yang baru mengeliminasi perbedaan tas sehari - hari dan tas untuk kegiatan akhir pekan.

2. Kurangi

Kurangi ukuran tas yang terlalu besar

3. Tingkatkan

Fleksibilitas material yang dapat beradaptasi dengan barang bawaan. Harga yang premium

4. Ciptakan

Penambahan fungsi tas yang dapat dipakai untuk dua kegiatan aktivitas. Penciptaan sistem mekanisme yang dapat merubah bentuk tas untuk aktivitas sehari dan aktivitas akhir pekan.

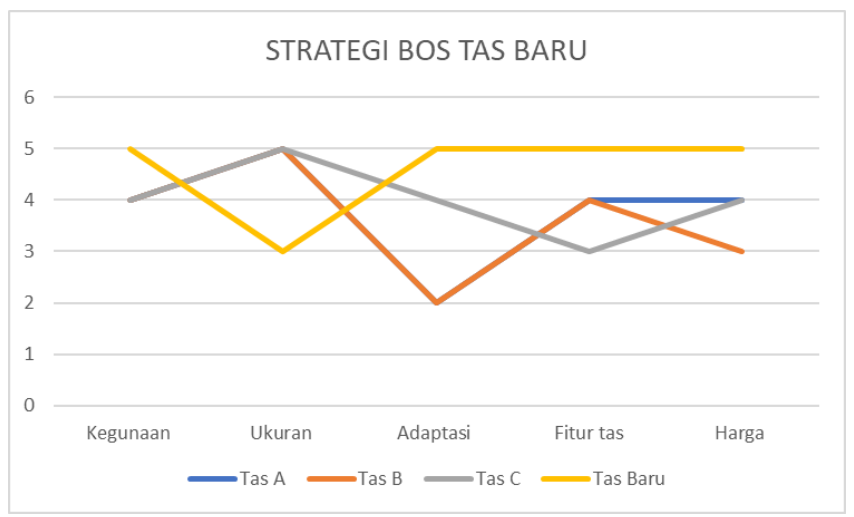

Gambar 5. Strategi BOS pada desain tas baru.

Konsep tas yang baru adalah tas yang dapat diubah bentuk dan ukurannya sesuai dengan volume barang bawaan, sehingga bisa digunakan untuk aneka aktivitas rutin dan aktivitas akhir pekan.

Dari kerangka berpikir ini dibuat berbagai alternatif desain seperti dapat dilihat pada Gambar-gambar 6, 7, dan 8 .

\section{Alternatif Desain 1}
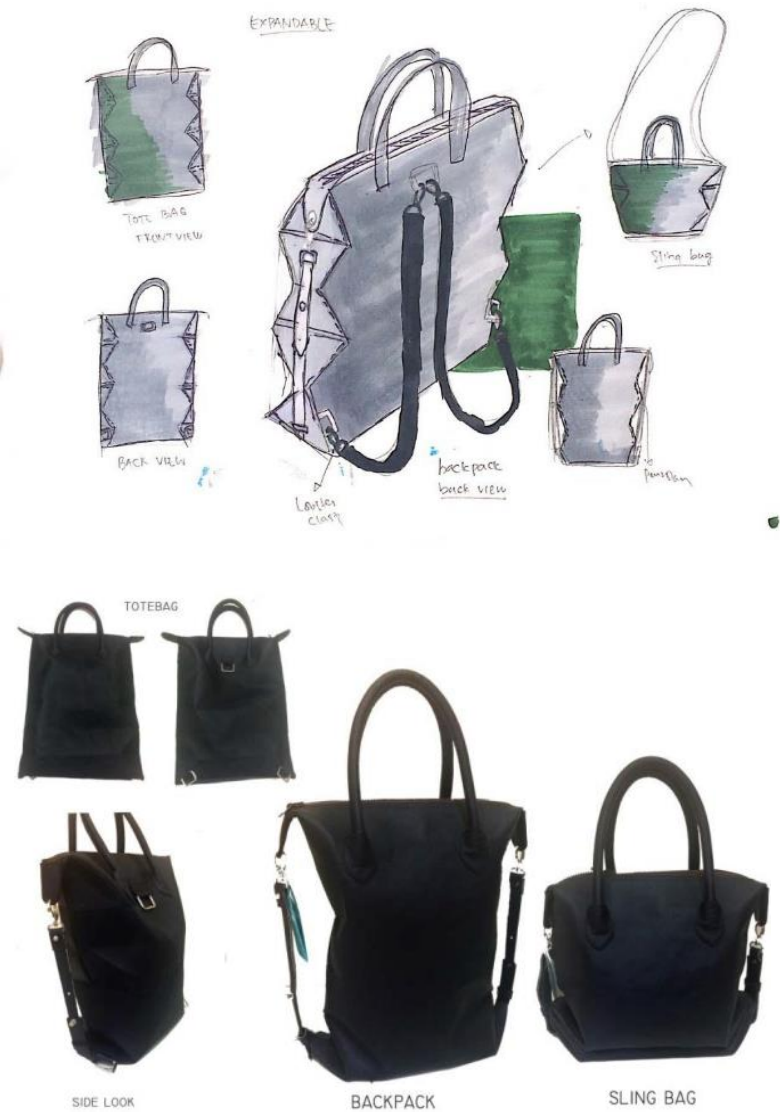

Gambar 6. Alternatif desain 1

\section{Alternatif Desain 2}
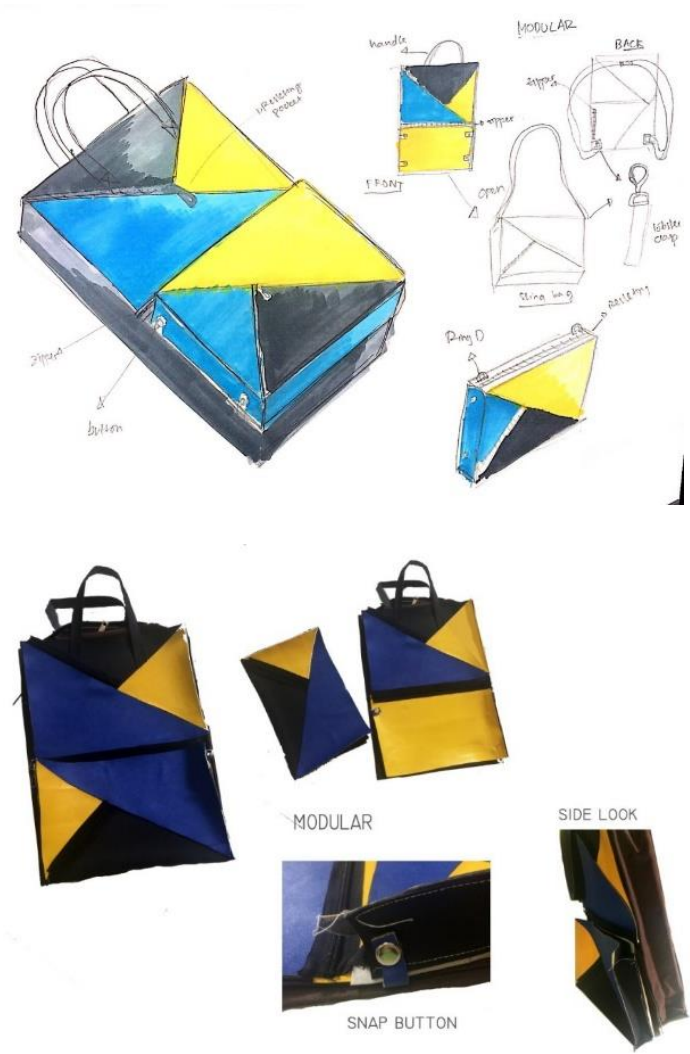

Gambar 7. Alternatif desain 2. 


\section{Alternatif desain 3}
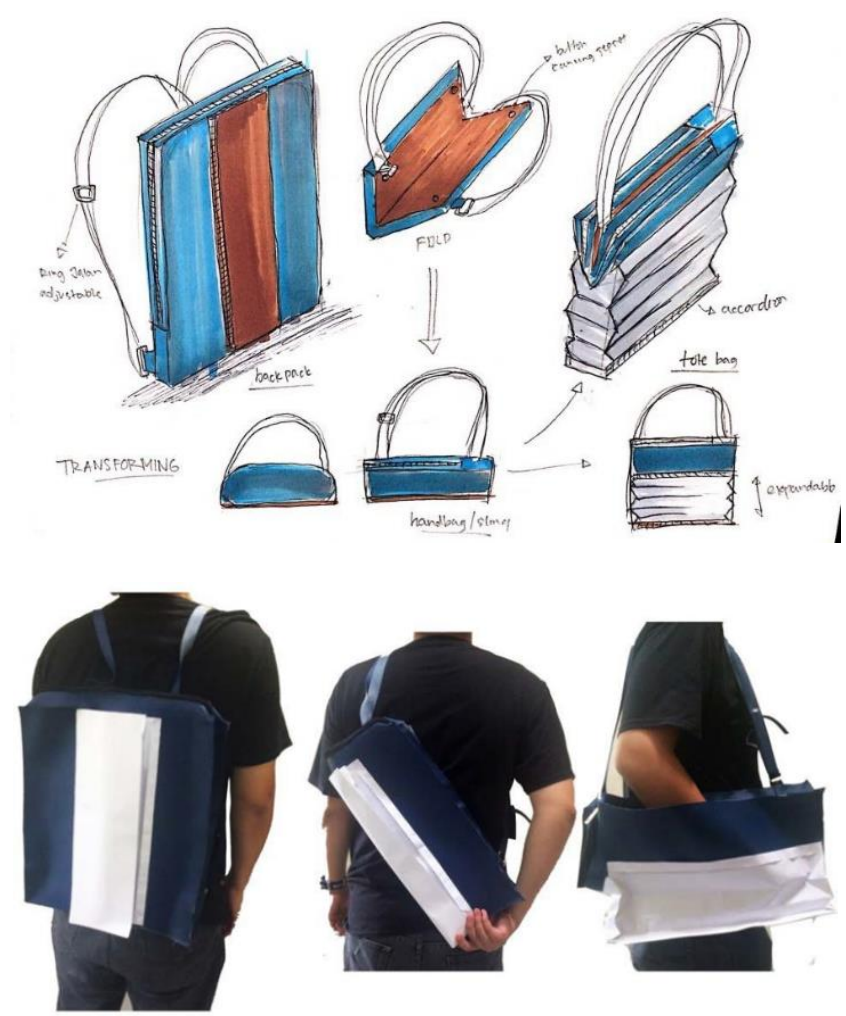

Gambar 8. Alternatif desain 3

\section{Final desain}

Dari ketiga alternatif desain dianalisa desain yang paling dapat menciptakan BOS, dan fitur dari masing - masing alternatif dipelajari agar didapatkan hasil yang maksimal.

Desain terpilih adalah yang ketiga, melihat kepraktisan dan dari satu tas didapat tiga tipe tas, sehingga pengguna dapat memilih tipe tas yang di inginkan disesuaikan dengan aktititasnya. Jadi tas dapat digunakan untuk aktivitas kuliah, olah raga, dan rekreasi akhir pekan (Gambar-gambar 9, 10, 11, 12 dan 13).

Bentuk tas pertama : tas punggung untuk aktivitas kuliah
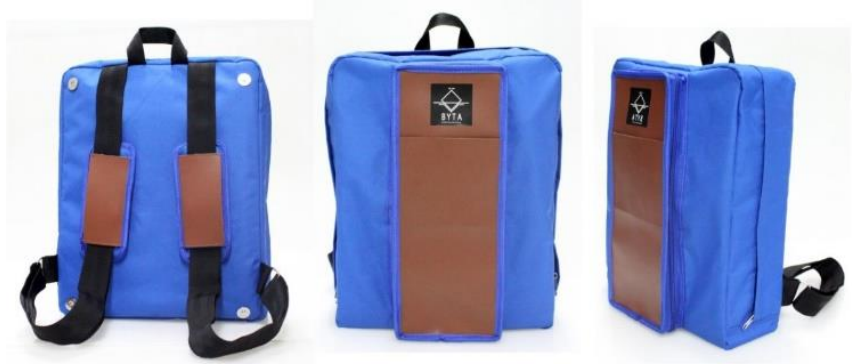

Gambar 9. Bentuk tas pertama: tas punggung untuk kuliah.

Bentuk tas kedua : sling bag

Bila ingin diperkecil tas dapat dilipat dan dikunci dengan magnet dan dapat dipakai sebagai sling bag.

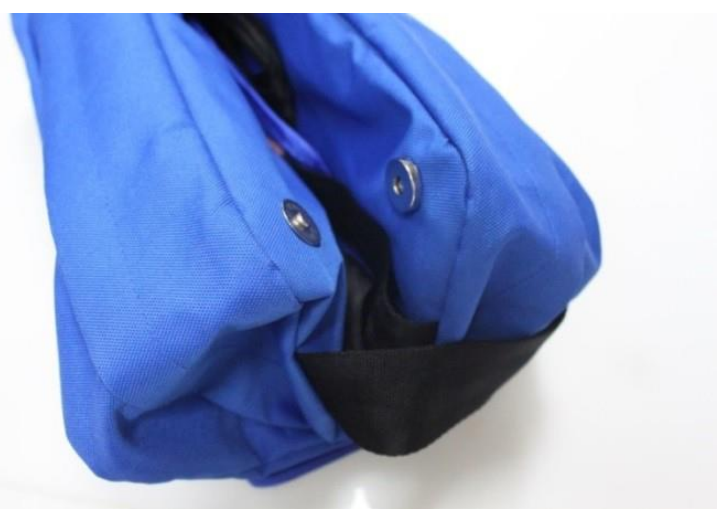

Gambar 10. Bentuk tas kedua; sling bag.

Bentuk tas ketiga: postman bag
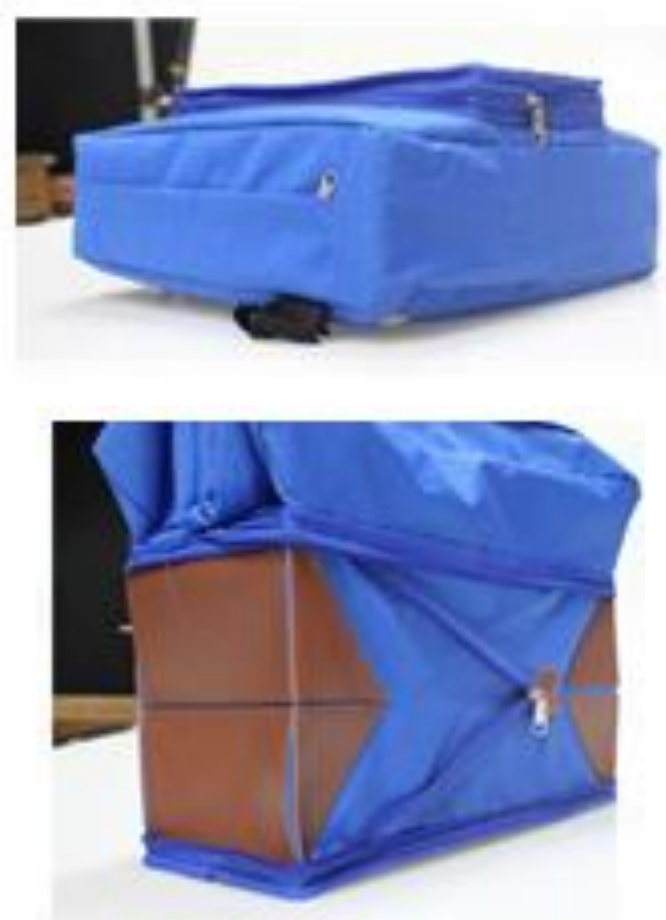

Gambar 11. Bentuk tas ketiga: postman bag.

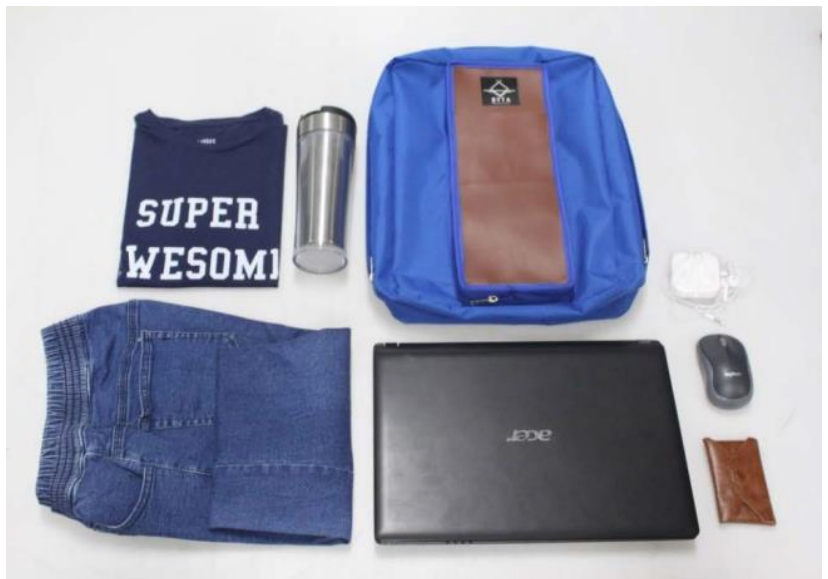

Gambar 12. Barang-barang yang dibawa (isi tas). 


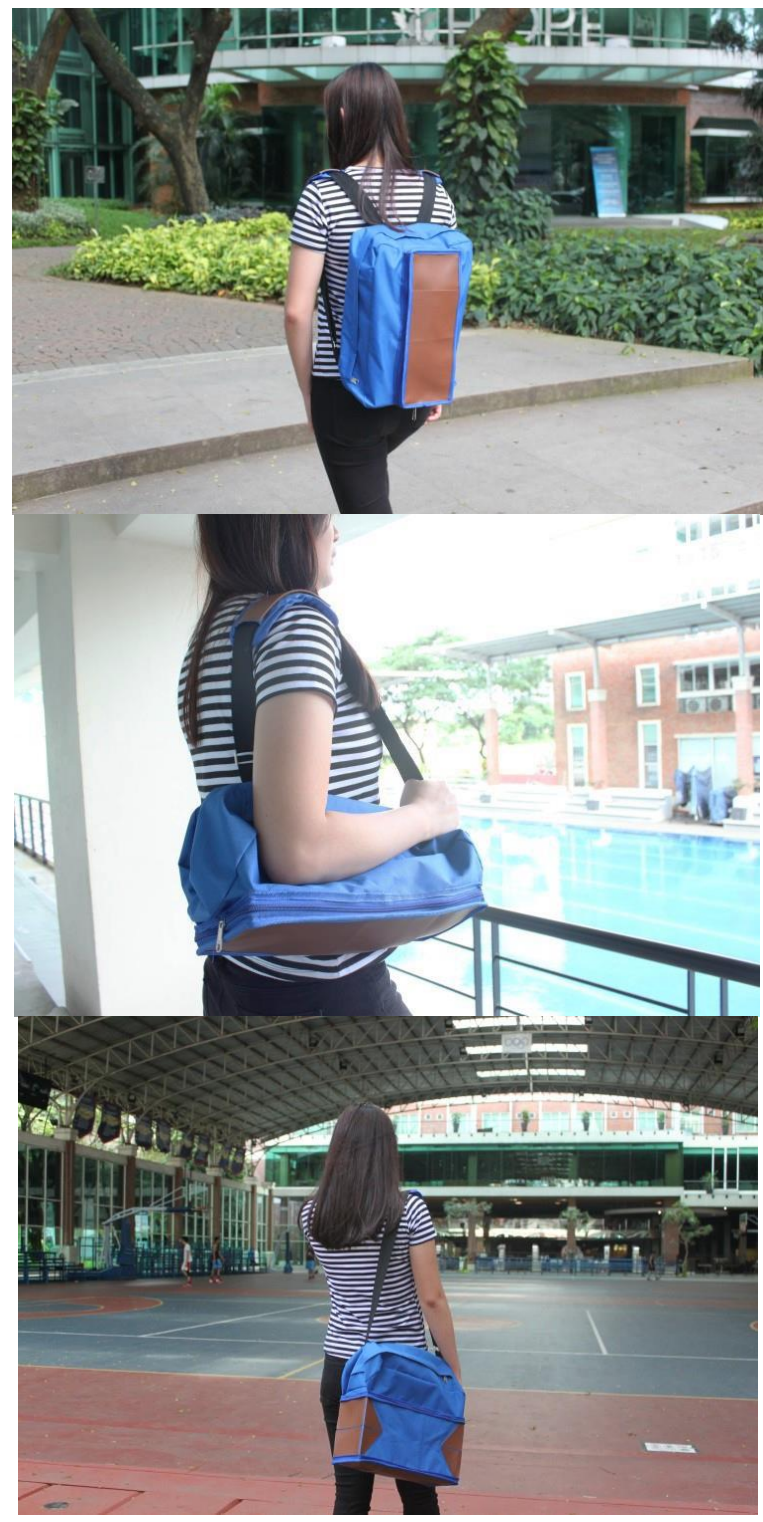

Gambar 13. Gambar suasana penggunaan produk tas.

\section{KESIMPULAN/RINGKASAN}

Dengan pendekatan BOS proses desain dan pencarian ide menjadi lebih terarah dan fokus, dengan mengetahui di variabel mana fitur - fitur desain perlu di hilangkan, dikurangi, ditingkatkan dan diciptakan. Fitur - fitur desain didapatkan berdasarkan hasil observasi, wawancara dan kuisoner. Dengan pendekatan ini menghasilkan desain desain baru yang belum pernah dilhat sebelumnya dan menciptakan pasar baru, tas yang dapat dipakai untuk aneka aktivitas mulai dari kuliah hingga acara akhir pekan.
Desain produk yang memang naturnya selalu mencari kebaruan pada proses desain, agar menghasilkan produk inovatif yang menciptakan kebutuhan baru dan pasar. sangat cocok didekatkan dengan BOS sangat direkomendasikan bagi para desainer untuk mulai menerapkan BOS dalam proses desainnya. Dengan memikirkan variabel apa yang perlu dieleminasi, dikurangkan, ditingkatkan dan diciptakan, akan keluar konsep desain yang unik dan berbeda dengan produk sejenis, tapi masih dapat diterima di pasar. Desain saat ini sedang dalam proses pengajuan HAKI Desain Industri untuk melindungi keunikan desain dengan pendekatan BOS.

\section{UCAPAN TERIMA KASIH}

Penulis ingin mengucapkan terima kasih atas bantuan, bimbingan serta kerjasama dari berbagai pihak yang telah membantu dalam penyusunan karya ilmiah ini. Khususnya penulis menyampaikan terima kasih kepada staf dan karyawan Fakultas Desain dan LPPM Universitas Pelita Harapan.

Artikel ini merupakan bagian dari publikasi penelitian internal UPH dengan no. No. 006/SOD-UPH/V/2019 dan terdaftar di LPPM UPH.

\section{DAFTAR PUSTAKA}

[1] Kim, W. Chan, and Renée Mauborgne. 2004. Blue Ocean Strategy. Harvard Business Review 82: 76-84

[2] Warell, A. (2015). Identity references in product design: An approach for inter-relating visual product experience and brand value representation. Procedia Manufacturing, 3, 2118-2125

[3] Kim, W. C., \& Mauborgne, R. (2014). Blue ocean strategy, expanded edition: How to create uncontested market space and make the competition irrelevant. Harvard business review Press. towards Communicating Strategies", in: Digital Proceedings of Conference on Visualising and Presenting Indicator Systems, Neuchatel, Switzerland, Swiss Federal Statistical Office.

[4] Kim, W. C., \& Mauborgne, R. (2017). Blue ocean shift: Beyond competing-proven steps to inspire confidence and seize new growth. Hachette UK.

[5] N. Cross, "Engineering Design Methods, Strategies for product design", Second Edition (John Wiley \& Sons Ltd, Baffins Lane, Chichester, West Sussex, PO19, England, 1998)

[6] M. Ashby, K. Johnson, "Materials and design, the art and science of material selection in product design" (Butterworth Heinemann, Oxford, UK, 2007)

[7] H. Christians and A. Bremmer, "Applied ergonomics", 29, 3, 201-211 (1998) 